\title{
A discussion of the term digital tectonics
}

\author{
I. K. Andersson ${ }^{1} \&$ P. H. Kirkegaard ${ }^{2}$ \\ ${ }^{1}$ Department of Architecture, Aalborg University, Denmark \\ ${ }^{2}$ Department of Civil Engineering, Aalborg University, Denmark
}

\begin{abstract}
For almost twenty years, digital architecture of different themes and characters has been produced. Through this time it has become possible to develop new and geometrically free forms, as well as calculate and simulate different technical matters of future constructions using digital tools. The wildest and most complex building concepts can through three-dimensional modelling and drawing programmes be realized and built, and this has naturally fascinated architects. Many digitally conceived projects are thus characterized by this fascination of the free-form geometry. In the contemporary discussions of digital architecture, digital tectonics is a commonly occurring term, and in this article the focus will be on this particular term. The term of tectonics has been used by architectural theorists for several centuries, but through time there have been many different opinions on what the term contains. In this article the term tectonics will first be defined through analysing of different architectural theories, and thereafter the term will be discussed in relation to digital architecture. Through this discussion a comprehension of the terms of tectonics and digital architecture is reached, and subsequently it is suggested how they together can form a new kind of tectonics - digital tectonics.
\end{abstract}

Keywords: tectonics, digital tectonics, digital architecture, performative architecture.

\section{Introduction}

During the recent decades Kolarevic [1], digitally designed buildings of different themes and characters have been produced. Through this time, it has become possible to develop new and geometrically free forms, as well as to calculate and simulate different technical matters of future constructions. The wildest and most complex building concepts can through three-dimensional modelling and 
drawing programmes be realized and built, and this have naturally fascinated architects. Many digitally conceived projects are thus characterized by this fascination of the new kind of shapes. Now, however, the digital tools have been used for a couple of decades in the architectural sphere, and the first fascination of the new geometrical possibilities is decreasing. Therefore it is interesting to take a look at the state of digital architecture, and evaluate what has come out of the use of digital tools until now. In the contemporary discussions of digital architecture, digital tectonics is a commonly occurring term.

The term of tectonics has been used in architectural theory for several centuries, and the word originates from Greek culture and language, where it has two main meanings in the area of architecture; the theory of the inner structure of a work of art, and the shaping and joining of form-elements to a unity. Through this time, several theorists, such as Karl Bötticher, Gottfried Semper, Eduard Sekler, and Kenneth Frampton, have discussed the term of tectonics. The main point from Bötticher's treatise on tectonics is, that every work of architecture, can be divided into Kerneform and Kunstform; the structural and the representational (Hartoonian [2]). Tectonics is according to Bötticher the system or concept that ties all the elements of a building together to a whole (Frampton [3]). Semper, too, makes a division between the technical and the symbolic issues, but also puts focus on the importance of coherency between material, and method of manufacturing. He divides the building into four fundamental elements; the hearth, the earthwork, the framework, and the screen wall, which are all either technical or symbolic (Hartoonian [2]). Furthermore, Semper regards the knot as being the oldest and most original constructional part (Frampton [3]). Therefore the joint is crucial for Semper, and in his opinion, it is out of the transitions between building elements, that the beauty of architecture emerges. Frampton proposes that tectonics is a means to reveal the essence of a building. Therefore he suggests logic constructions, in order to clarify the structure of a piece of architecture, and make it immediately understandable. Also in Frampton's theory the joint has a prominent place - the joint is where elements and materials meet, and it is therefore a crucial point in the telling of the logic of a construction. In the joint, the story of materials, overall structure, and laws of nature is embedded, and it thus the most tectonic element of an architectural artefact (Jameson [5]).

When considering the terms digital and tectonics, one might come to the conclusion that they are contradicting each other (Leach [6]). The digital is comprehended as virtual, abstract and free of the laws of nature (Liu et al. [7]), while tectonic is tactile, concrete, and, as earlier described, arising as a reaction of the laws of nature. Therefore it might immediately be difficult to see, how these two can be combined, and how one at all can speak of such a term as digital tectonics. What might then be contained in the term of digital tectonics? Just as in the case of tectonics there are numerous of different opinions on how the term of digital tectonics should be interpreted. One of the suggestions of how to describe the term digital tectonics is "the poetics of digitally conceived, structurally clarified and directly manufactured architecture" (Jabi [8]). At times the description is even reduced to "the poetry of digitally constructed 
assemblages" (Jabi [8]), but the question is how it then relates to the traditional meaning of tectonics. Where in a piece of digitally conceived architecture is one supposed to look for the concrete signs of digital tectonics? This article contains analyses and reflections on the term of digital tectonics. Through presentation and discussion of existing theories on tectonics and digital tectonics, an understanding of the similarities and discrepancies between the two matters of are proposed.

\section{Digital tectonics}

The new techniques and tools that are available through computer programmes can both be used in an aesthetic manner, to handle complex compositions of shapes, but also in the engineering area, as described in the previous section on optimisation, which makes it is possible to find precise solutions through complex models of the building and its conditions. These new possibilities in terms of complex visual and spatial systems have enabled architecture to remain abstract, often at the expense of construction and materials (Beesley and Seebohm [9]).

The new possibilities of digital creation of geometrically free forms are today inspiring many architects to build curvilinear. The stylistic break caused by the emergence of digital tools, has thus resulted in architecture that seemingly rejects the notion of structural technology, continuity, and morphology. The architects of this movement represent an ideological, conceptual and formal break with the building tradition (Kolarevic [1]), and use the classical, or representational, approach to architecture. One of the architects that can be placed in the classical appearance orientated digital architecture is Frank Gehry (Leach [6]). Gehry preferably uses a tactile physical model, instead of a digital manipulation of surfaces on a computer screen. Therefore his use of digital technologies can be seen as a translation of physical models, into digital information that can be used in the final fabrication of the building (Kolarevic [1]). In many cases the computer has been used to replace the manual tools of the architect - the drawing board, the clay-model, the slide rule etc. - in the production of traditional architectural drawings. Hereby one of the major advantages of using the computer is neglected; the possibility of generating geometric forms that are not directly controlled by the designer. Greg Lynn is one of the first architects to use animation software for generating form, instead of generating representations of future buildings; for instance force fields were used to generate and transform structures (Kolarevic [1]). As an example of this method of working can be mentioned Bernhard Franken \& ABB Architekten's the BMW Pavilion from 1999 (Figure 3). The formal foundation of this building is two spheres lying apart from each other. A force field, drawing them closer to each other, is added to the scene. The spheres start to move and eventually they melt together into a unified form. This method can be used for both generating completely free form, but if placing force fields in the scene that relates to the character of the site or actual loads on the building, such as wind-loads, the generated form will get more project-specific and begin to relate to the term of tectonics. 
In the area of technological aspects of a building - such as construction, acoustics, lighting, climate, etc. - the digital tools provide great possibilities for exploration and simulation of future conditions, as well as engineering optimisation, as mentioned in last chapter. In the City Hall of London, drawn by Foster and Partners, there are for instance made solar studies, to investigate how the sunbeams will be distributed over the building's surface, and different shapes are tested in relation to the acoustics of the interior, before the final shape of the building is found (Whitehead [10]). With these kinds of possibilities of conducting research before actually building a piece of architecture, the expectations on building design are redefined. The demands are getting higher and there is a new emphasis on building performance, for example in relation to economics, spatiality, culture, ecology, and technology (Kolarevic [1]).

Another example that can be mentioned is the National Swimming Centre drawn by PTW Architects in 2003 for the Olympics in Beijing 2008 (Figure 3), in cooperation with Arup Engineers and China State Construction Engineering Cooperation $\mathrm{a}+\mathrm{u}$ [11]. The concept is based on the three-dimensional structure of water foam, which defines both the constructive and spatial system of the building AV [12]. Thus the building can be explained as a cube of water molecules, in which there are carved out spaces for different functions - a watercube.

As implied in the examples of the BMW Pavilion, London City Hall and The National Swimming Centre the generative processes can be opened up to the new conceptual, formal, and tectonic possibilities of exploration that lies in digital tools, with focus on the adaptability of form. Hereby the digital tool provides what seems to be the notion of the digitally based techniques - the shift from making of form to the finding of form (Kolarevic [1]). When using the word finding in this context, it is not meant to suggest that the optimal shape is supposed to be found and copied directly from a technical computer programme. Such a solution is called a mechanical solution, as the architect would not have any influence on the completely computer-generated result. To reach a tectonic result, a machinic solution must be found, i.e. the process must contain computational technical aspects as well as architectural aesthetic considerations (Leach [6]). The computer is then used as a collaborative partner, that give the architect technical guidelines through the process.

With offset in both the aesthetic and the technical sphere Branko Kolarevic introduces the concept of performative architecture. This is a term signifying architecture that should perform especially well in some areas, such as acoustics, indoor climate, or construction, and therefore needs analysing on the matter, and accordingly adaptation of the architectural form (Schmidt [13]). When bringing the technical and the representational aspects together in a process where the technical analyses are allowed to be highly influent on the shaping of a building, the process will have great tectonic potential. Philip Beesley and Thomas Seebohm also relate to both the ontological and the representational, when arguing that digital tectonics is "a systematic use of geometric and spatial ordinances, used in combination with details and components directly related to contemporary construction" (Beesley and Seebohm [9]). Hereby they suggest 
that the architect should work with geometrical structures, as a foundation, or main idea, for the building, and then use the knowledge and technologies available to communicate these notions and structures trough the concrete design of details and components. Neither Kolarevic's nor Beesley and Seebohm's suggestions is very different from the earlier descriptions of tectonics in relation to the interaction between construction, material and expression, but there is a new emphasis on téchne in relation to the process, through which a project is being shaped, and the knowledge and use of new technologies and tools. It is here that the digital tectonics can be found - in the unified process where the architect turns into a modern tekton, who can overview and control all, both technological and aesthetic, aspects of the building.

\section{Clarification of the term of tectonics by examples}

In the following, three architectural works (Figure 1) will be evaluated in relation to tectonics, in order to get a more concrete comprehension of the term, and to define the discrepancies and similarities between the earlier mentioned theorists - Bötticher, Semper, Sekler and Frampton. To get a comparable result of the discussions, the main points of each theorist is pinned up in a table, which is filled out for each of the architectural works (Figure 2). The buildings are evaluated trough the table and get a green dot, if they fulfil the main points of the theorist, and red dot if they do not. The first building is Ludwig Mies van der Rohe's Barcelona Pavillion of 1929, hereafter follows Jørn Utzon's Bagsværd Church of 1977, and last Jean Nouvel's Institute du Monde Arabe of 1987. These three buildings represent different movements of the last century and thus also different approaches to tectonics.

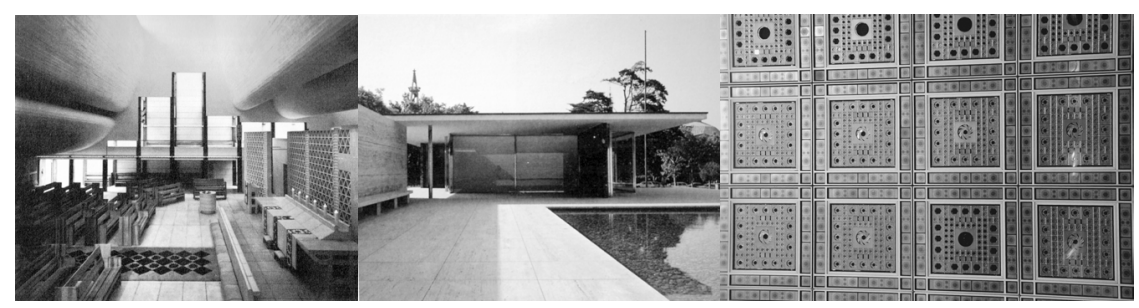

Figure 1: Pictures of the buildings used in the comparison. From right to left - Interior of Bagsværd Church; Exterior of Barcelona Pavilion; and the façade of Institute du Monde Arabe.

From (Figure 2) it is clear to see, that the theorists do not quite agree on what tectonics is. Therefore it is interesting to find out whether or not there is a centre of interest that the theorists have in common. To start with, all of the theorists suggest a division of architecture into a concrete part and a more abstract part. To the concrete part belong construction, method, and material, whereas in the abstract part belong structure, concept, representation, and intensification. Semper and Frampton primarily proposes that the concept of a building is told 
through the transitions - the joints, while Bötticher and Sekler is more general in their suggesting that the construction is articulated by respectively a unifying concept, and intensification by tectonics.

BÖTTICHER
Keywords: Structure
and symbol / Unifying
concept
The Barcelona Pavilion
There is a delicate balance be-
tween structure and symbol in
the Barcelona Pavilion. The
symbols are embedded in the
materials of the building ele-
ments, and the beauty lies in
the small details. The concept
is built upon the modernistic
thoughts of illusive spaces
and volumes and this is car-
ried out through the whole
construction.

SEMPER

Keywords: Material and method / Details and joints

The Barcelona Pavilion The materials and methods of manufacturing are coherent and much of the quality of the building lies in the choice of materials. The transitions between elements are kept very simple, but they are very well articulated, in relation to showing the transition of forces.
Bagsværd Church

In Bagsværd Church both the structural and representational parts are clearly articulated. The concept for the building is also clear and construction and symbol melts together to a whole.

\section{Q Bagsværd Church The transition from wood to concrete (Semper's Stoffwechseltheorie) has been handled with care. The undulating ceiling, however, might have been more simply manufactured in metal truss work. The overall structure is an illustrative example of Semper's hearth (alter), earth- work, framework, and screen wall. The joints between the different elements are simple and clear and one can thus understand how the building is coping with the forces.}

Keywords: Structure and Construction / Intensification by tectonics

The Barcelona Pavilion The structure and the conconstruction is working according to the main concept, but the construction is not immediately comprehensible, as the transitions of forces between the building elements are not visible. The intensification by tectonics is apparent throughout the building, as all details is working in favour of the modernistic concept.

Bagsvaerd Church

There is consistency between the structure and the construction in the framework of the building, but as earlier mentioned, the ceiling might have been more simply constructed in metal truss work. There is though an intensification of tectonics, for example in the merging of the columns into the strengthening screen wall.

\section{SEKLER} struction are coherent, and the
FRAMPTON

Keywords: Clear structure / Elaboration of joints

The Barcelona Pavilion The construction of the building is simple and is in itself quite logic. The joints, however, are not telling the story about the logic of the construction; the columns are rather floating between the roof and the floor and one cannot conceive a transition of forces in the joint between them. They do though tell the story of the concept and thus reveal the essence of the building in a less technical manner.

\section{Bagsverd Church}

The structure of the church is clear and comprehensible and the joint are well elaborated. One can understand the logic and the symbolic concept of the building, when experiencing it.

Institut du Monde Arabe The structure is not immediately comprehensible, at least not seen from the outside. One can understand that there is something, force resistant behind the screen, but it is not possible to see what it consists of. The joints are beautifully detailed, in a simple and

delicate manner. and the symbols are separated,

so that they can be conceived individually.
Institut du Monde Arabe The way, in which the Islamcornament is transformed into an electronic aluminium screen, is an excellent example of Semper's Stoffwechseltheorie, and one must admit that Nouvel uses the materials and methods according to their qualities. Also the details are delicately elaborated - simple and coherent.

Institut du Monde Arabe
The structure is frame-curtain
wall, and the construction is
clearly showing the curtain
wall, whereas the framework
is only seen in some parts of
the building. The intensifica-
tion by tectonics is indeed
present in the building, where
the elaborate aluminium com-
position takes up of much of
the attention.
the attention.

Figure 2: Table containing evaluation of three pieces of architecture in relation to four theorists - Bötticher, Semper, Sekler and Frampton. Tectonically correct $Q$ Tectonically incorrect

Looking chronologically on the development of theory on tectonics, one can through the four mentioned theorists see a moving towards an emphasis of clear and comprehensible construction. This might be a reaction to the abundance of materials and construction types available today. With the emergence of 
computer technology it is made possible to couple almost any material with any constructions, as constructions can be dimensioned in detail, before building them, and materials can be modified and appropriately reinforced, in order to meet the demands of the architect.

\section{Clarification of the term of digital tectonics by examples}

In order to find similarities and discrepancies in how the concepts of tectonics and digital tectonics are being comprehended an evaluation - similar to the comparison of buildings in relation to tectonics - of three digitally conceived works of architecture (Figure 4) is done. From the previous discussion on the term of tectonics to central issues are picked out: Material and construction / Structural logic.

Neither the term of digital tectonics is divided into any sub-categories. Because the term digital tectonics is relatively new, there are no such established and elaborate theories on the subject, as there are for traditional tectonics. Therefore some general keywords on the matter of digital tectonics are picked out from the discussion of the previous pages: Performative architecture / Clear and logic structures.

The buildings that will be evaluated with offset in these keywords are Walt Disney Concert Hall, in Los Angeles, by Frank Gehry; the BMW Pavilion, by architects Bernhard Franken and ABB Architekten; and the National Swimming Centre, by PTW (Figure 3). These represent widely different approaches to the new possibilities given by the emergence of digital tools.

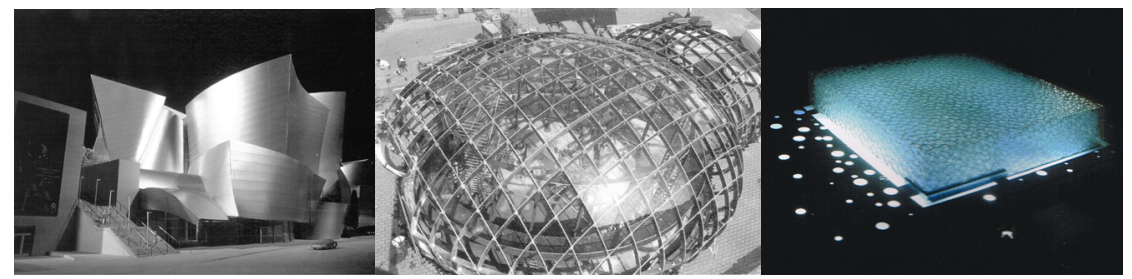

Figure 3: Three digitally designed and built buildings - Walt Disney Concert Hall, The BMW Pavilion, and the National Swimming Centre.

From these comparisons it is possible to distinguish the differences between the traditional and the digital tectonics, as it is comprehended today. Only by looking at the chosen keywords one can see, that the first discrepancy; traditional tectonics is more tangible and concrete, with its emphasis on detailing in relation to the used materials and constructions, whereas digital tectonics emphasises the iterations and interaction between aesthetic and technical aspects in the formfinding process and is thus more abstract and process oriented. Having said this, the first similarity is as well apparent. Both the traditional and the digital tectonics is clearly a way of expression the fusion between art and technology the phenomenological and the positivistic. This is the core in the definition of tectonics, explaining what the concept of architecture is all about. The art of building is an art form that arises as a response to context, science, and forces. 


TECTONICS
Keywords: Material and Construction / Structural
logics

Walt Disney Concert Hall

The sheet metal cladding of the facades are a logical choice for the desired expression and construction as it is formable and relatively light. The inner structure is technically logic, but it is not displayed to the observer in order to make the building comprehendible, but is rather considered a hidden means to achieve the desired sculptural expression. Therefore the structure and material of the bearing and stabilising construction have no impact at all, on the expression of the building.

\section{The BMW Pavilion}

The structure is logic, in relation to the strong geometrical notion that is chosen for the building. Even though the desired geometry dominates the process, the chosen materials prevents the geometry to obscure the structure in the realized building. The materials and the construction are well chosen for the purpose, The details are elaborate and simple in order to express high-quality finish and elegance.

DIGITAL TECTONICS

Keywords: Performative architecture / Clear and logic structures

Walt Disney Concert Hall

The actual concert hall is highly performative architecture, and has also been treated as such. The acoustics is thoroughly investigated and the shape is adjusted according to the results of the technical analysis, with aesthetics and technology working together. The structures are, as earlier mentioned, logic, but cannot be considered to be clear, as they are hidden behind the sheet metal curtain walls.

\section{The BMW Pavilion}

The performance of the architecture is here tied to the spatial and expressive aspects, which entirely define the shape and the constructions. The geometry is found and hereafter the bearing structures are designed to suit the sacred shape. Therefore there is no mutual impact between the shape and the results of the technical analyses. The structure can be considered be applied to the sacred form, as a subordinate element, and thus it rather works for the shape, instead of with it. The construction is simple in order to submit to the shape, rather than being clear, in order to show the logics of the forces. The lack of interaction between technology and representation during the proces makes the BMW Pavilion digitally atectonic.

The National Swimming Centre

The materials and the construction are inseparable - it would be possible to build the construction with other materials than those, that are used. The structures are created from the water foam concept, and is then transformed into a building construction. It is geometrically logic, and understandable, through the bubble metaphor.
Whe National Swimming Centre

The building has been developed through investigation on how the water foam structure can act as constructive and spatial system as well as facades. The result of these investigations is a logic and poetic interpretation of water foam.

Figure 4: Table containing evaluation of three pieces of architecture in relation to tectonics and digital tectonics. Tectonically correct $\boldsymbol{Q}$ Tectonically incorrect

In the case of the $B M W$ Pavilion, the whole geometry is generated and chosen, with offset in models, which have neither materials applied, nor thickness of the surfaces - it is purely given its shape from aesthetic considerations. Surely there are forces in the scene, that helps generating the geometry, but those forces are, positivistically speaking, arbitrary forces, as they are chosen and inserted by the designer. Even gravity can be considered an abstract force in a model without material properties, and is therefore also a matter of aesthetic choice of the designer. There is not necessarily a logic hierarchy of the applied forces in relation to the real laws of nature, i.e. the conceptual attraction of the two spheres in the $B M W$ Pavilion is equal to the force of gravity in the digital world.

In relation to the Walt Disney Concert Hall, the shape is in some ways aesthetically chosen, without considerations on the technical aspects, especially not the actual bearing of the hall, but the geometry is not holy, and can thus be changed in relation to the technical analysis. The basic shape is also impacted by the acoustical experiments from the early phases of the design process. Even though there have been technical considerations and analyses during the design process, the aesthetic shape is most certainly obscuring the structures of the 
building. The forms of the building do by no means disclose how the building is born and stabilized. The sheet metal gives the building a sculptural and shell-like expression, but the underlying construction is actually a lightweight latticework of steel. This is a very atectonic aspect of the building, as it is not possible to experience the flow of forces through building elements and joints. The new $\mathrm{CAD} / \mathrm{CAM}$ technologies have made these complex constellations possible, but unfortunately, the elegance and preciseness of the constructions that the techniques enable, are not a part of the building's expression.

When looking at the process from which the National Swimming Centre has been designed and produced, it is clear that technology and aesthetics have worked together, in order to create a unified whole. This is a good example of performative architecture. The process gives rise to a lifting of architecture to a higher level - a level where the building can both be technically correct and artistically handled. The results from technical analyses are constructively and artistically worked into the design, and they are therefore an important design parameter, rather than an appliquè to a form. The process is hereby a hybridprocess, with architects and engineers working closely together in a digital continuum. PTW has used the computer technology to create unconventional architecture, by using nature to find a system that is transformed into a building system with help from the computers. Hereby they redefine and challenge the traditional building elements, walls, columns, window etc. At the same time, they use a system that we humans recognise as porous and stable - foam - that makes the building seem both logic and poetic.

Considering these different aspects of the digital and the tectonic, it is suggested that the digital tectonic should arise as mixture of the concrete and the abstract. The traditional term of tectonics is not quite enough, when evaluating digitally conceived architecture, as it does not detect the atectonic process. The tectonic process have become more relevant, since the emergence of computers, as it is now possible to create a logic construction to each and every desirable form, as seen in the example of the BMW Pavilion. On the other hand, the digital tectonics, as it is described through the keywords in the comparison, does not mention the relation between construction and material. This should, as Heidegger [14] points out, be the corner-stone in all aesthetics, and the interaction between construction and material is obviously an important aspect of revealing the truth of the nature of loads, forces and material properties - in it lies the whole comprehension of what it means to construct and build. Thus it is proposed that the central issues in terms digital tectonics should be: Interaction between material and construction, Clear and logic structure, Performative architecture.

\section{Conclusion}

Through this paper the terms tectonics and digital tectonics have been discussed in order to find out how they can be comprehended, and how they can be used in the architectural field today. Tectonics has been used in architectural theory for several centuries, and the term both refers to the concrete and the abstract aspects 
of the art of building. The main issues, contained in term tectonics, are suggested to be the interaction between material and type of construction, and the communication of the logics of the chosen structure. The former of these relates to the ontological aspects of building, and the latter to the representational. With the emergence of digital architectural tools, it is interesting to see how the architects are using the new technology to change and improve the art of building. From the mentioned examples of digital architecture in the second and fourth section of this paper, it can be seen that the computer technology is used vastly differently by different offices. From looking at the processes, it is suggested that it is possible to reach a tectonic result, without having had an integrated and tectonic process, such as in the case of the BMW Pavilion. It is possible to find a logic structure and construction to every, desired and thinkable, geometry, without even once considering it in the form-finding process.

For the last decades it has also become possible to compose materials, with almost any thinkable properties combined. This in some ways changes the logics of construction, and therefore also the logics of tectonic structures. At the same time, the computer technology makes it possible to create structures that would have been impossible to manage before, as seen in the Walt Disney Concert Hall and National Swimming Centre. In the latter of these two pieces of architecture, the constructive and the spatial systems are intrinsically connected, and through this artistic and spatial interpretation of the laws of science and nature a tectonic poetry arises.

The new tectonics is though not just the challenging of the old building traditions and techniques, but also a matter of an integrated process. Digital tectonics is thus not just an addition of digital architecture to the traditional term of tectonics. It is a new way of considering architecture, as a clear and logic result of a hybrid-process. The deeper meaning of architecture and tectonics is still the same - it should still reveal the truth of the building and its context. The technical context is however changed because of the new possibilities that lie in the digital tools, and thus the notion of tectonics also has to change. Therefore Bötticher, Semper, Sekler, and Frampton's definitions of tectonic are not sufficient anymore. Another aspect has to be added - an integrated form-finding process. On the other hand, digital tectonics, as it is described through the keywords in the comparison, does not mention the relation between construction and material. The interaction between construction and material is an important aspect of revealing the truth of the nature of loads, forces and material properties - in it lies the whole comprehension of what it means to construct and build. It is therefore suggested that digital tectonics is a combination of Interaction between material and construction, Clear and logic structure, and Performative architecture.

\section{References}

[1] Kolarevic, B., Architecture in the digital age - Design and manufacturing, Spoon Press, 2003. 
[2] Hartoonian, G., Ontology Construction - On Nihilism of Technology in Theories of Modern Architecture, Cambridge University Press, Cambridge, 1994.

[3] Frampton, K. (edited by John Cava), Studies in a Tectonic Culture: The Poetics of Construction in Nineteenth and Twentieth Century Architecture, MIT Press, Cambridge Massachusetts, 1996.

[4] Sekler, E. F., Structure, Construction, Tectonics, in ed. Kepes, Gyorgy, Structure in Art and Science, Studio Vista, London, 1965.

[5] Jameson, F., The Constraints of Postmodernism, in ed. Leach, Neil, Rethinking Architecture, A reader in cultural theory, Routledge, Great Britain, 1997.

[6] Leach, N., Digital Tectonics, John Wiley \& Sons Ltd., West Sussex, 2004.

[7] Yu-T.L \& Chor-K.L., New tectonics: a preliminary framework involving classic and digital thinking. Design Studies 27(3), 2006

[8] Jabi, W., Digital Tectonics: the intersection of the physical and the virtual, Fabrication: Examining the Digital Practice of Architecture. Proceedings of the 23rd Annual Conference of the Association for Computer Aided Design in Architecture and the 2004 Conference of the AIA Technology in Architectural Practice Knowledge Community, Cambridge (Ontario) 814 November, 2004.

[9] Beesley, P. \& Seebohm, T. Digital Tectonic Design, Promise and Reality: State of the Art versus State of Practice in Computing for the Design and Planning Process. 18th eCAADe Conference Proceedings. Weimar (Germany) 22-24, 2000.

[10] Whitehead, H., Laws of Form, in ed. Kolarevic, Branko, Architecture in the digital age - Design and manufacturing, Spoon Press, London, 2003.

[11] a + u, no. 399, 03:12, Feature: Future in China, 2005.

[12] AV Monographs, PTW: National Swimming Centre, Beijing, 2004.

[13] Schmidt, A.M.D., Digital Tectonic Tools, Digital Design: The Quest for New Paradigms. 23rd eCAADe Conference Proceedings. Lisbon (Portugal) 21-24 September, 2005.

[14] Heidegger, M., (Translation by J. M. Lambert), Kunstværkets Oprindelse, Gyldendal 1994. 